


\title{
Tsunamis: geração e riscos
}

Autor(es): $\quad$ Carmo, José S. Antunes do

Publicado por: Associação Portuguesa de Riscos, Prevenção e Segurança

URL persistente:

URI:http://hdl.handle.net/10316.2/40109

DOI:

DOl:https://doi.org/10.14195/1647-7723_7_2

Accessed : $\quad$ 26-Apr-2023 16:08:48

A navegação consulta e descarregamento dos títulos inseridos nas Bibliotecas Digitais UC Digitalis, UC Pombalina e UC Impactum, pressupõem a aceitação plena e sem reservas dos Termos e Condições de Uso destas Bibliotecas Digitais, disponíveis em https://digitalis.uc.pt/pt-pt/termos.

Conforme exposto nos referidos Termos e Condições de Uso, o descarregamento de títulos de acesso restrito requer uma licença válida de autorização devendo o utilizador aceder ao(s) documento(s) a partir de um endereço de IP da instituição detentora da supramencionada licença.

Ao utilizador é apenas permitido o descarregamento para uso pessoal, pelo que o emprego do(s) título(s) descarregado(s) para outro fim, designadamente comercial, carece de autorização do respetivo autor ou editor da obra.

Na medida em que todas as obras da UC Digitalis se encontram protegidas pelo Código do Direito de Autor e Direitos Conexos e demais legislação aplicável, toda a cópia, parcial ou total, deste documento, nos casos em que é legalmente admitida, deverá conter ou fazer-se acompanhar por este aviso.

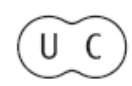




\title{
Tsunamis: geração e riscos
}

\author{
José S. Antunes do Carmo *
}

\begin{abstract}
Resumo:
Um tsunami é um trem de ondas, ou uma série de ondas, geradas numa massa de água por uma perturbação que desloca verticalmente a coluna de água. Os tsunamis podem ser gerados por sismos em regiôes costeiras e oceânicas, deslizamentos de taludes submersos, erupções vulcânicas, explosões ou ainda por impactos de corpos cósmicos, como meteoritos. Os tsunamis atingem períodos típicos da ordem de uma hora e comprimentos de onda superiores a $200 \mathrm{~km}$. Em consequência do seu grande comprimento de onda, um tsunami comporta-se como uma onda que se propaga em condiçốes de água pouco profunda. Ondas com estas características propagam-se com celeridade proporcional à raíz quadrada do produto da gravidade pela profundidade. Por outro lado, a "perda de energia" destas ondas é inversamente proporcional ao seu comprimento de onda; por conseguinte, os tsunamis não só se propagam a grande velocidade, como podem percorrer distâncias transoceânicas com uma limitada "perda de energia".

Palavras chave:

Riscos. Tsunamis. Sismos. Modelação numérica.
\end{abstract}

Résumé:

Un tsunamis (raz de marée) est un ensemble de houles créé dans une masse d'eau par une perturbation mouvant verticallement la colonne d'eau. Les tsunamis peuvent être générés par seismes sur les côtes océaniques, glissements de talus sous aquatiques, eruptions volcaniques, explosions ou par des impacts d'origine cosmique (météorites). Les tsunamis atteignent des périodes tipiques de l'ordre d'une heure et des longueurs de houle supérieurs à $200 \mathrm{Km}$. En conséquence de sa longueur de houle, un tsunami est une sorte de houle qui se propague dans des conditions d'eau peu profonde. Des houles avec ces caractéristiques se propaguent avec une vélocité proportionnelle à la racine carrée du produit de la gravité par la profondeur. De l'autre coté, la "perte d'énergie" de ces houles est inversement proportionnelle à sa longueur de houle; par conséquence, les tsunamis se propaguent pas seulement à une grande vélocité, mais aussi ils peuvent parcourrir des distances transocéaniques avec une "perte d'énergie" limitée.

Mots clés:

Risques, tsunamis, seismes, modélation numérique.

Abstract:

A tsunami is a series of waves generated in a body of water by an impulse disturbance that displaces vertically the water column. Tsunamis are primarily associated with earthquakes in oceanic and coastal regions. Landslides, volcanic eruptions, nuclear explosions, and even impacts of cosmic bodies, like meteorites, can also generate tsunamis. A tsunami can have a period of about one hour and a wavelength in excess of 200 $\mathrm{km}$. It is because of their long wavelengths that tsunamis behave as shallow-water waves. The speed of a shallow-water wave is equal to the square root of the product of the acceleration of gravity and the depth of the water. The rate at which a wave "loses its energy" in inversely related to its wavelength. Since a tsunami has a very large wavelength, it will "lose little energy" as it propagates. Hence in very deep water, a tsunami will travel at high speeds and travel great transoceanic distances with limited "energy loss".

Key words:

Risks. Tsunamis. Earthquakes. Numerical simulation.

\section{Introdução}

Associa-se normalmente a geração de um tsunami à ocorrência de um sismo. Embora esta associação seja provida de fundamento, não corresponde inteiramente à verdade. Com efeito, um tsunami pode ser causado por um movimento numa falha ou por um deslocamento da crosta terrestre ao longo de uma fractura. Este movimento causa um sismo e pode também provocar uma alteração do equilíbrio da massa de água situada sobre o fundo perturbado e consequentemente gerar uma perturbação na superfície livre do oceano. Todavia, nem todos os tipos de movimentos são susceptíveis de gerar tsunamis. Apenas

* Departamento de Engenharia Civil da Faculdade de Ciências e Tecnologia da Universidade de Coimbra. um deslocamento vertical provoca desequilíbrios na coluna de água situada sobre a falha ou zona de fractura, dando origem à procura de um novo equilíbrio. Por conseguinte, os movimentos lateral e horizontal igualmente associados às transformações da crosta terrestre e frequentemente causadores de sismos geralmente não produzem tsunamis, pois não provocam alterações significativas na massa de água.

Outras fontes igualmente geradoras de tsunamis são erupções vulcânicas, explosões nucleares e avalanches ou deslocamentos de taludes submersos produzidos em zonas de fractura ou falhas activas.

Os tsunamis resultam assim, fundamentalmente, em consequência de descargas de energia libertada na crosta terrestre, ao longo do fundo oceânico, que é sucessivamente transferida em energia potencial ao longo da coluna de água situada acima da área 
fonte e convertida na propagação horizontal da perturbação assim gerada na superfície livre do oceano.

Tipicamente, os tsunamis são gerados a profundidades da ordem dos $3000 \mathrm{~m}$ a $5000 \mathrm{~m}$ e possuem comprimentos de onda da ordem dos $200 \mathrm{~km}$. Uma onda com estas características propaga-se pelo oceano em condições ditas de água pouco profunda. Ainda em conformidade com a teoria das ondas, a velocidade de propagação de um tsunami é dada por $C=\sqrt{g h}$, sendo $g$ a aceleração da gravidade $\left(g=9.805 \mathrm{~ms}^{-2}\right)$ e $h$ a profundidade local. Deste modo, considerando uma profundidade média $h=4000 \mathrm{~m}$, ter-se-á $C \approx 198 \mathrm{~ms}^{-1}>700 \mathrm{kmh}^{-\mathrm{i}}$.

Ao largo, na zona de geração, os tsunamis são caracterizados por alturas típicas da ordem de $1.0 \mathrm{~m}$. Por conseguinte, estas ondas não são verdadeiramente observáveis antes de atingirem as proximidades da costa, a distâncias na ordem da dezena de quilómetros, e, mesmo a esta distância, só com alturas de onda da ordem dos $8 \mathrm{~m}$, ou superiores.

Por outro lado, devido ao efeito de redução da profundidade na plataforma continental, a velocidade de propagação de um tsunami diminui consideravelmente junto à costa; todavia, a altura deste é significativamente empolada para muito mais do dobro da altura ao largo, atingindo frequentemente alturas na ordem dos $10 \mathrm{~m}$ ou mais, conduzindo em geral à rebentação.

Durante o seu percurso, o fluxo da energia de um tsunami mantém-se sensivelmente constante, sendo a conservação deste fluxo o resultado de um equilíbrio entre a velocidade de propagação e a altura da onda. Uma redução de qualquer destas variáveis implica um aumento da outra, o que, no caso de um tsunami, se traduz no aumento da sua altura ao propagar-se sobre profundidades decrescentes.

\section{Exemplos históricos de tsunamis}

Em termos globais, a ocorrência de tsunamis, tanto em número como em importância e efeitos destrutivos, segue uma distribuição muito próxima da dos sismos.

Com efeito, o Oceano Pacífico é tectonicamente o mais activo e também o oceano com maior incidência de tsunamis, sendo aí geradas cerca de $80 \%$ das ondas de maiores dimensões.

As Figuras 1 e 2 evidenciam não só a distribuição dos sismos com magnitude superior a 5.0 na escala de Richter, ocorridos em todo o Globo na década de 80 , como a coincidência dos locais de ocorrência (epicentros) com as fronteiras das placas tectónicas, sendo particularmente importantes as distribuições verificadas nos Oceanos Pacífico e Atlântico.

A grande maioria dos tsunamis que ocorrem no Oceano Pacífico está relacionada com as actividades sísmicae vulcânica, sendo particularmente importantes e devastadores os tsunamis gerados ao longo do designado "Anel de Fogo", justamente em consequência daquelas actividades.

São gerados anualmente muitos tsunamis de pequenas dimensões. Historicamente, um tsunami já com forte poder destrutivo ocorre em parte incerta do Globo em cada período de dois a três anos. Um tsunami de elevadas proporções, com características devastadoras, ocorre em cada período de quinze a vinte anos.



Figura 1 - Distribuição dos sismos ocorridos no período de 1980-1990 com magnitudes iguais ou superiores a 5.0 na escala de Richter (Adaptado de THURMAN e TRUJILLO, 1999). 


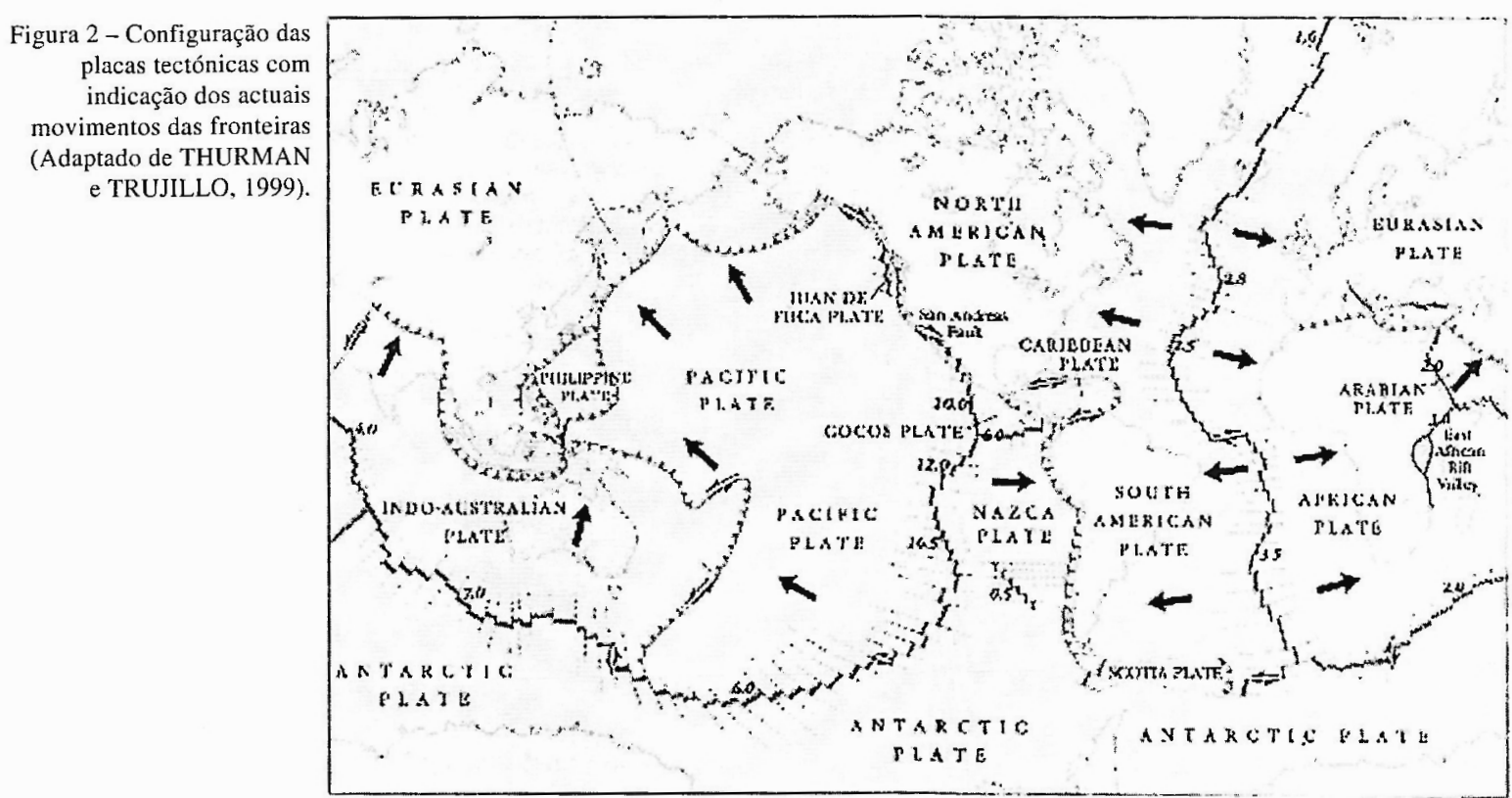

\subsection{Tsunamis com elevado poder destrutivo}

Em Agosto de 1883 aconteceu um dos mais destrutivos tsunamis de que hámemória. Em consequência de uma explosão ocorrida na ilha vulcânica de Krakatau (ou Krakatoa), situada a Oeste da ilha de Java-Indonésia, o deslocamento da massa de água devido à energia libertada durante a explosão deu origem a um tsunami que atingiu cerca de 35 metros de altura. A onda gerada devastou por completo a região costeira de uma ilha situada entre as ilhas de Sumatra e de Java, destruindo cerca de 1000 aldeias e provocando mais de 36000 vítimas.

Para se ter uma ideia do poder destrutivo desta onda bastará referir que a energia por esta transportada atingiu todas as bacias oceânicas, tendo sido detectada em registos de maré situados em Londres e S. Francisco.
Em consequência de um sismo que ocorreu em Abril de 1946 no Alaska, com a magnitude 7.3 na escala de Richter, gerou-se um tsunami que atingiu o porto de Hilo, no Hawaii, com uma altura superior a 17 metros, tendo provocado prejuízos elevadíssimos (cerca de 26 milhões de dólares) e vitimado cerca de 165 pessoas.

As fotografias que se apresentam na Figura 3 foram obtidas nas proximidades do porto de Hilo e são bem reveladoras do poder destrutivo deste tsunami.

Nas proximidades do epicentro a altura da onda gerada foi estimada em cerca de 36 metros, tendo provocado diversas vítimas e destruído vários edifícios e veículos.

Em Novembro de 1952, um tsunami gerado na Península de Kamchatka-Rússia com magnitude 8.2 provocou uma inundação com altura superior a $1.0 \mathrm{~m}$






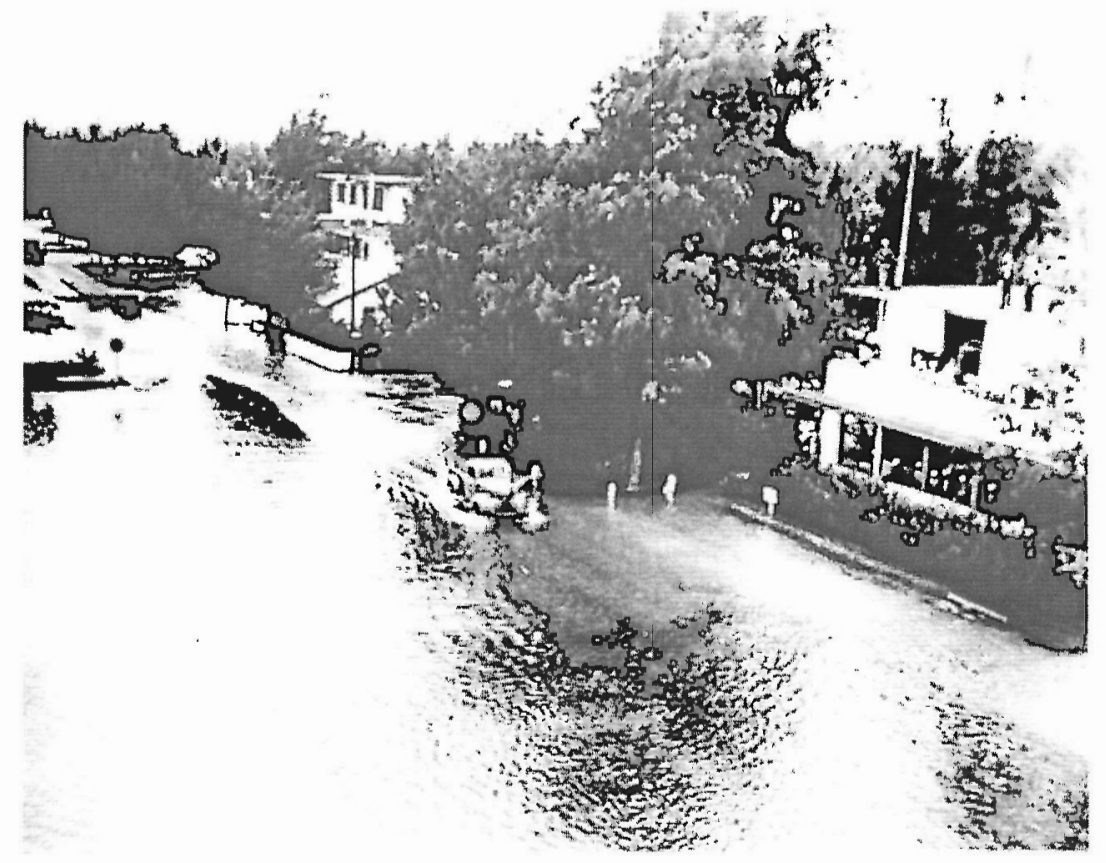

Figura 4 - Tsunami gerado na Península de Kamchatka-Rússia: cheia provocada na ilha de Midway, situada a cerca de $3000 \mathrm{~km}$ de distância (www.geophys.washington.edu).

na ilha de Midway, situada a cerca de $3000 \mathrm{~km}$ de distância, e prejuízos no Hawaii estimados em cerca de 1 milhão de dólares. A Figura 4 mostra a cheia numa artéria da ilha de Midway provocada pela passagem deste tsunami.

Em Março de 1957, as ilhas Hawaiianas foram de novo atingidas por um tsunami com epicentro nas ilhas Aleutian-Alaska e magnitude 8.3. Os prejuízos elevaram-se a mais de 5 milhões de dólares. Na ilha de Haena as ondas atingiram os $16 \mathrm{~m}$ de altura e no porto de Hilo os níveis de água elevaram-se a cerca de 4 metros, tendo danificado vários edifícios. A sequência de duas imagens que se apresenta na Figura 5 é bem reveladora da enorme enchente que se seguiu.
Um sismo ocorrido em 1960, com epicentro no Chile e magnitude 8.3 na escala de Richter, gerou um tsunami que atingiu o estado do Hawaii, tendo perecido 61 pessoas. Este $t$ sunami destruíu mais de 500 edifícios e provocou prejuízos na ordem dos 23 milhões de dólares.

Em Março de 1964 ocorreu um sismo com epicentro no Alaska, em Prince William Sound, e magnitude 8.4. O tsunami gerado em consequência de deslizamentos atingiu uma altura superior a $30 \mathrm{~m}$, tendo causado 122 vítimas e provocado prejuízos que ultrapassaram os 105 milhões de dólares.

Em Novembro de 1975, um tsunami gerado em consequência de um sismo com epicentro na costa

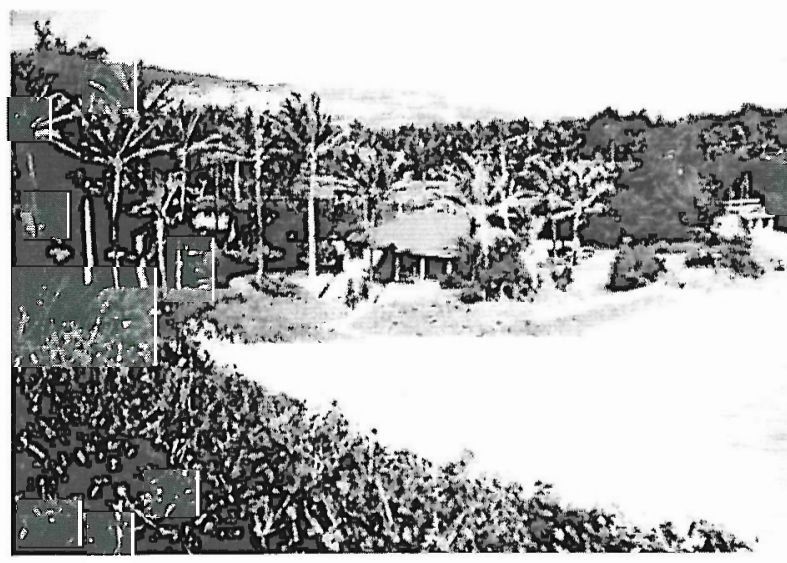

Figura 5 - Tsunami gerado nas ilhas de Aleutian-Alaska em 1957: sequência de fotografias da chegada da primeira onda à ilha de Oahu-Hawaii, a cerca de $3600 \mathrm{~km}$ de distância (www.geophys.washington.edu).

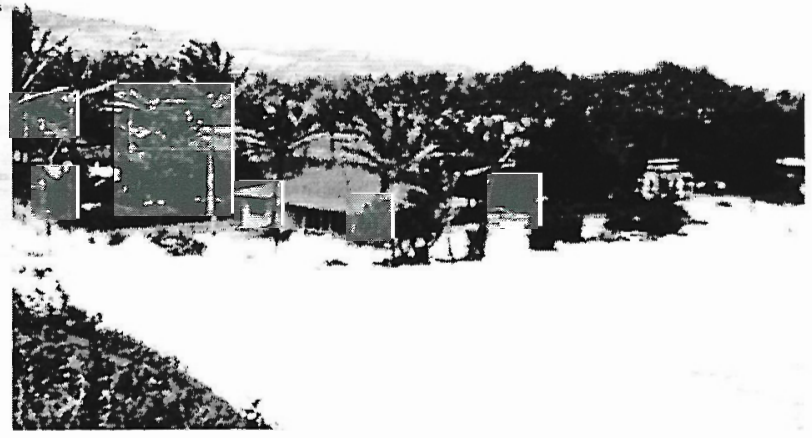


Hawaiiana magnitude 7.2 atingiu uma altura próxima dos $8.0 \mathrm{~m}$ provocando diversas vítimas e elevados prejuízos materiais.

Para se ter uma ideia mais clara da frequência e intensidade deste fenómeno, bastará referir que ocorreram no Oceano Pacífico, apenas nos anos de 1981 a 1997,62 tsunamis gerados por sismos com magnitude superior a 6.0 na escala de Richter. De entre estes, 23 tsunamis foram gerados por sismos que atingiram magnitudes iguais ou superiores a 7.5 naquela mesma escala.

\subsection{Tsunamis importantes que atingiram Portugal}

Na costa Portuguesa, os períodos de recorrência de tsunamis gerados por sismos com idênticas magnitudes são incomparavelmente superiores. Da ordem de quatrocentos anos para um tsunami já com algum poder destrutivo (sismo com magnitude 7.5 a 8.0 na escala de Richter) e superior a mil anos para um tsunami com características destrutivas e modificadoras da linha de costa, como o ocorrido em 1755 (sismo com magnitude 8.5 a 9.0 na mesma escala).

Pelas 9 h e $30 \mathrm{~m}$ do dia 1 de Novembro de 1755 ocorreu o mais devastador tsunami que atingiu a costa Portuguesa, com uma magnitude estimada em 8.5 na escala de Richter.

De acordo com um relato da época, é possível extrair a seguinte passagem: "Pelas nove horas e meia da manha começou a terra a tremer, (...), durante este terremoto meio quarto de hora, (...) passado discurso de meia hora, (...) começou este a levantar tais montes de água, (...) encheu por 3 ou 4 vezes, foram os maiores fluxos e refluxos..." (in GOMES PAULINO, 1997).

Ainda de acordo com relatos da época, transcreve Pereira de Sousa (1919) a seguinte passagem relativa à chegada deste tsunami a um dado lugar junto à costa Portuguesa “...Pelo Ribeiro de agoa doce que ali desagua na praia, entrou o marno dia do terramoto por espaço de mais de _legua (cerca de 2 500-3000 $m$ ) em altura de 10 a 12 varas (cerca de $11-13 \mathrm{~m}$ ), arrazando huns grandiosos médãos de areia, onde estavam 50 ferros dos mais pezados pertencentes à armação que ali se lança, os quaes arrastou a mais de hum quarto de legua (cerca de $1250-1500 \mathrm{~m}$ ) terra dentro..." (in GOMES PAULINO, 1997).

Por estas passagens é não só possível avaliar o poder destrutivo do tsunami, como identificar algumas das características típicas deste fenómeno.

$\mathrm{Na}$ Figura 6 apresenta-se parte do fundo oceânico, em particular o Banco de Gorringe (G.B.), cuja actividade é geradora de sismos e de potenciais tsunamis que podem afectar a costa Portuguesa.

Mais recentemente, em 28 de Fevereiro de 1969, um sismo com magnitude 7.9 na escala de Richter gerou um tsunami que afectou as costas Portuguesa, Espanhola e Marroquina. Embora associado a um sismo com algum poder destrutivo, este tsunami não teve consequências de registo.

Foram sobretudo as comparações e os estudos efectuados com base nos registos deste segundo tsunami que permitiram identificar não sóa localização do epicentro do sismo que lhe deu origem, como também localizar o epicentro do sismo que deu origem ao tsunami de 1755 .
Figura 6 - Principal região dos fundos oceânicos (Atlântico) cuja actividade é sentida com alguma intensidade no território Português (Cortesia de Proença Cunha).

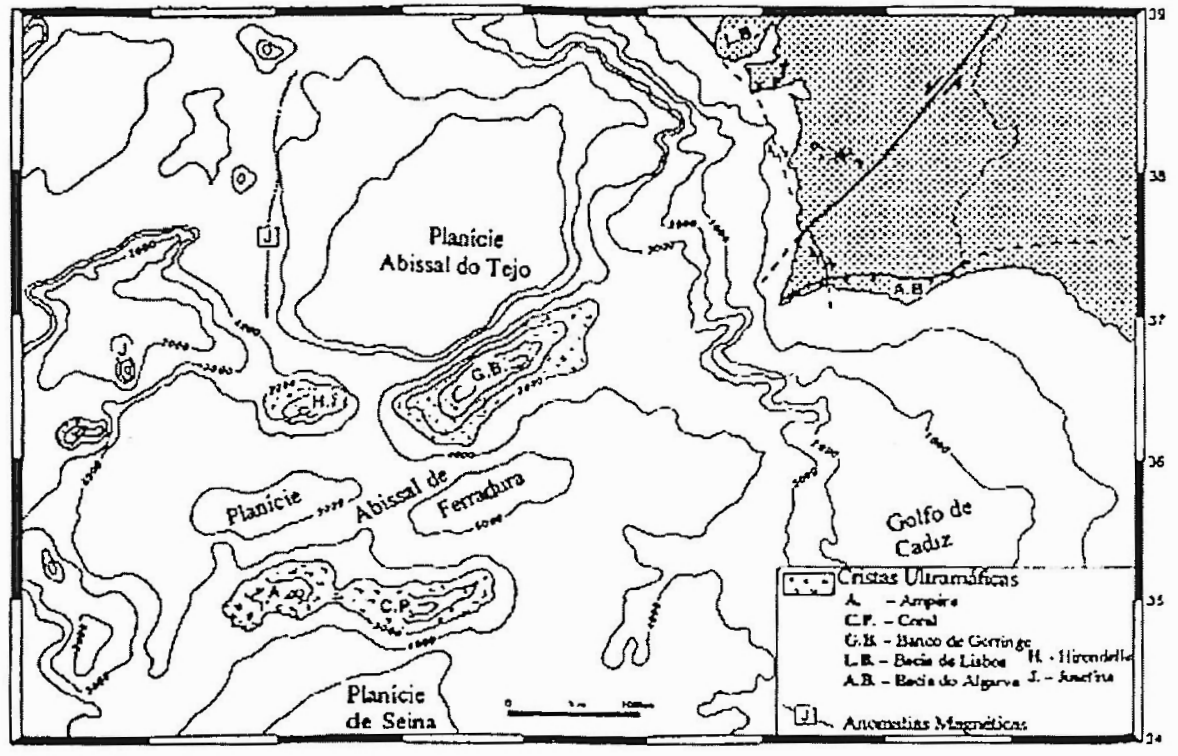




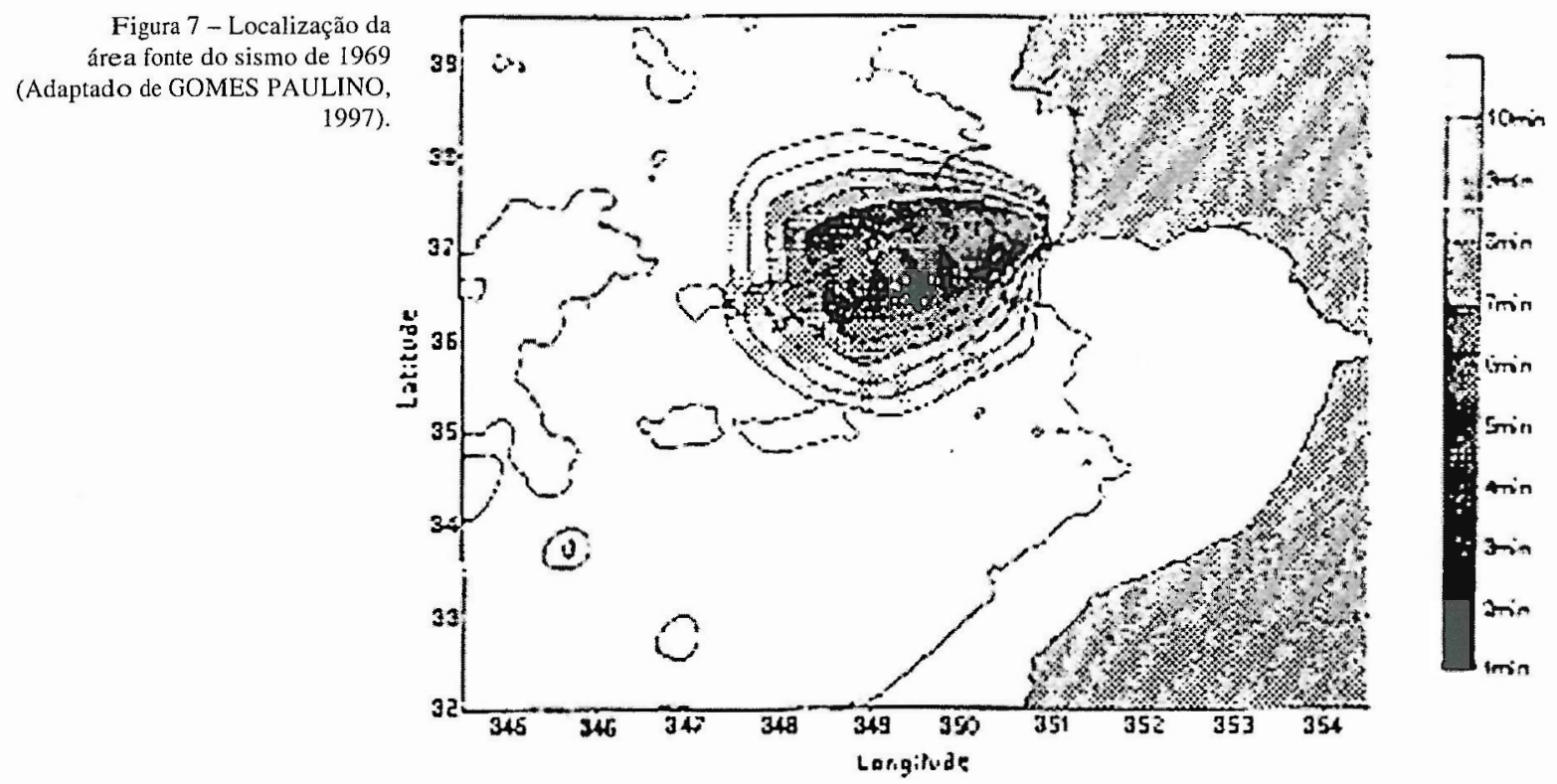

Os tempos de chegada da energia associada ao tsunami de 1969 , registados em estações situadas na linha de costa e complementados com outros estudos, permitiram identificar a área fonte deste sismo. Estudos idênticos foram realizados para o tsunami de 1755 , tendo sido identificada a mesma área fonte (região do Banco de Gorringe). Na Figura 7 apresenta-se o resultado de um estudo efectuado para a localização da área fon te do sismo de $1969 \mathrm{e}$, consequentememte, também do tsunami a que deu origem.

\section{Geração e propagação de um tsunami}

Tendo como objectivos mostrar o processo de geração de um tsunami e avaliar algumas das características deste fenómeno, simula-se um exemplo teórico de libertação da energia resultante do deslizamento de um talude submerso, situado a cerca de 250 metros de profundidade. A consequente transferência da energia libertada em energia potencial ao longo da coluna de água provoca à superfície livre do domínio considerado uma perturbação que se propaga em sentidos opostos, sendo particularmente importante a onda que se dirige no sentido da costa, a cerca de $30 \mathrm{~km}$ de distância.

Um modelo matemático adequado para a reprodução deste fenómeno tem por base um sistema de equações do tipo Boussinesq, aqui estendido a variações temporais do fundo. Em variáveis dimensionais, estas equações escrevem-se:

$$
\begin{aligned}
& \frac{\partial h}{\partial t}+\frac{\partial(h u)}{\partial x}=0 \\
& \frac{\partial u}{\partial t}+u \frac{\partial u}{\partial x}+g \frac{\partial \eta}{\partial x}-\frac{(H-\xi)^{2}}{3} \frac{\partial^{3} u}{\partial x^{2} \partial t}+\frac{(H-\xi)}{2} \frac{\partial u}{\partial t} \frac{\partial^{2} \xi}{\partial x^{2}}+(H-\xi) \frac{\partial^{2} u}{\partial x \partial t} \frac{\partial \xi}{\partial x}+ \\
& \quad+\frac{\partial \eta}{\partial x} \frac{\partial^{2} \xi}{\partial t^{2}}+\frac{\eta}{2} \frac{\partial^{3} \xi}{\partial x \partial t^{2}}+(H-\xi) \frac{\partial u}{\partial x} \frac{\partial^{2} \xi}{\partial x \partial t}+\frac{(H-\xi)}{2} \frac{\partial^{3} \xi}{\partial x \partial t^{2}}+ \\
& \quad+(H-\xi) u \frac{\partial^{3} \xi}{\partial x^{2} \partial t}-v \frac{\partial^{2} u}{\partial x^{2}}-\frac{\tau_{s}}{h}+\frac{\tau_{f}}{h}=0
\end{aligned}
$$

em que: $h$ e $u$ representam a profundidade local e a velocidade média doescoamento; h representa variações da superfície livre; $H$ representa cotas da superfície livre relativamente a um dado referencial; $x$ representa cotas de fundo; $n$ representa a viscosidade cinemática do fluido; $t_{s}$ e $t_{f}$ representam tensões de atrito por unidade de massa na superfície livre e no fundo, respectivamente.

Este sistema de equações é resolvido numericamente, utilizando um método de elementos finitos para a discretização dos termos com variações espaciais e um método de diferenças finitas para a resolução das variações temporais.

Apresentam-se nas Figuras 8, 9 e 10 imagens da superfície livre e resultados obtidos em sondas numéricas, em consequência do deslizamento de um talude submerso situado a cerca de $30 \mathrm{~km}$ da linha de costa. A primeira imagem da Figura 8 mostra as configurações iniciais do fundo e da superfície livre; a segunda 
Figura 8 - Configurações iniciais do fundo (a tracejado) e da superfície livre (a cheio) e as mesmas configurações três minutos após o início do deslizamento de um talude submerso durante cerca de vinte segundos.

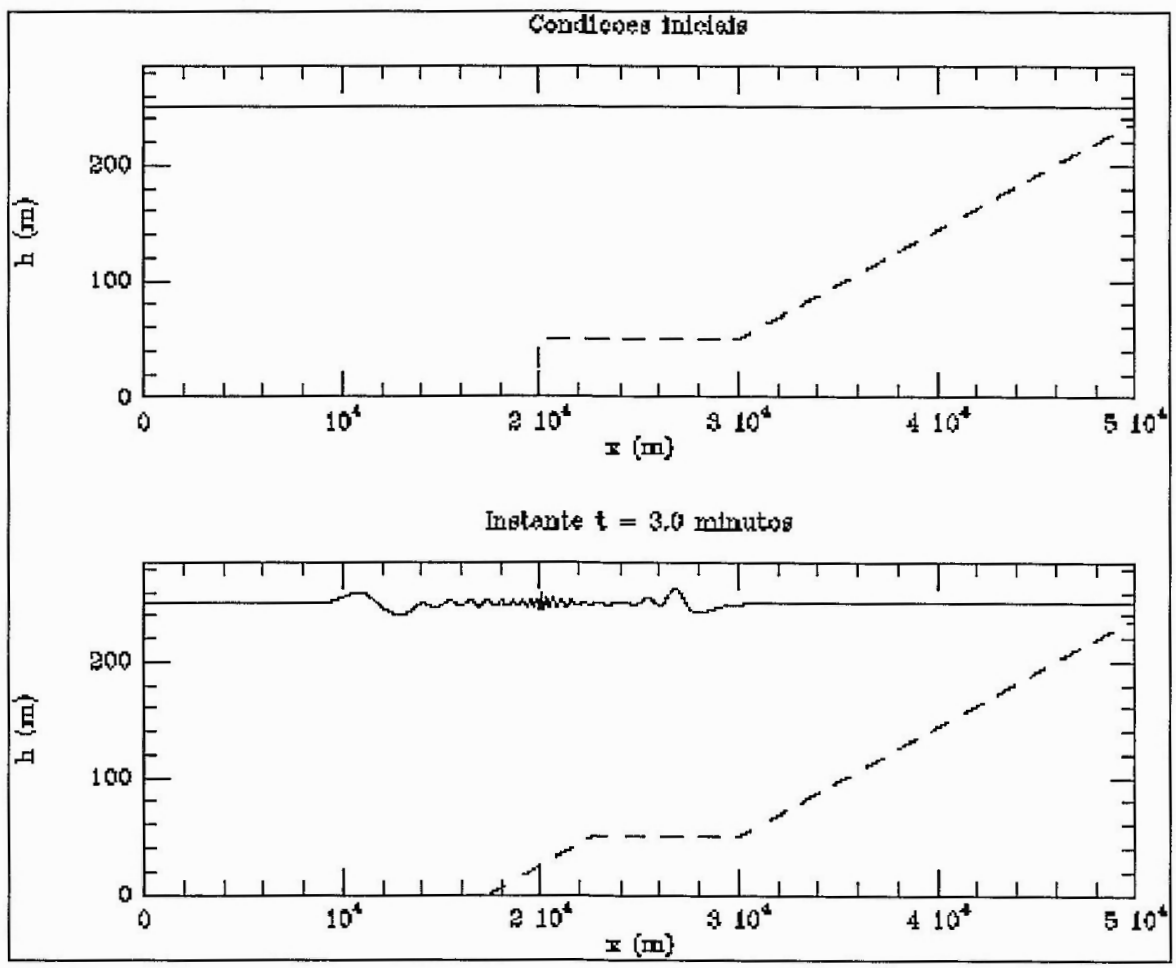

Ingtarte $t=8$ minutos

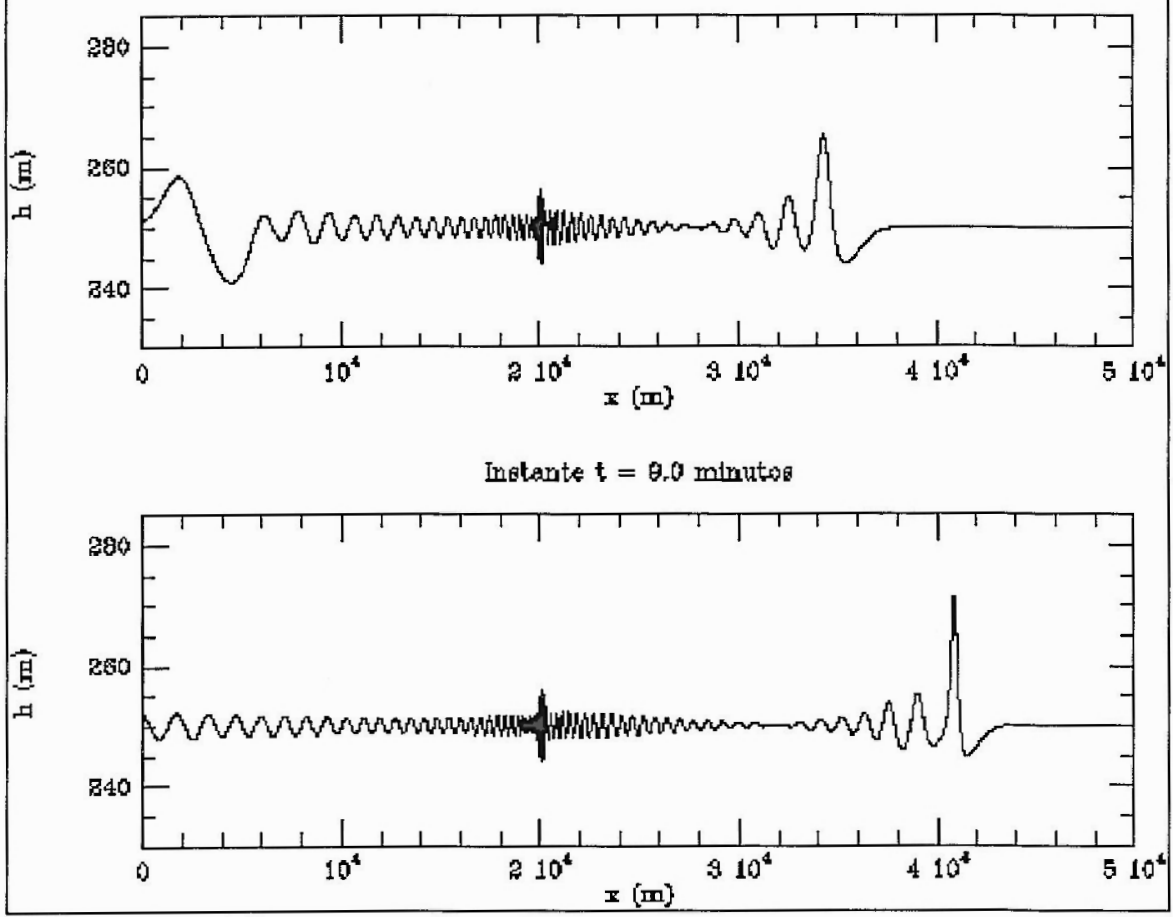

Figura 9 - Superfície livre aos seis minutos e aos nove minutos após o início do deslizamento de um talude submerso, a cerca de $250 \mathrm{~m}$ de profundidade. 


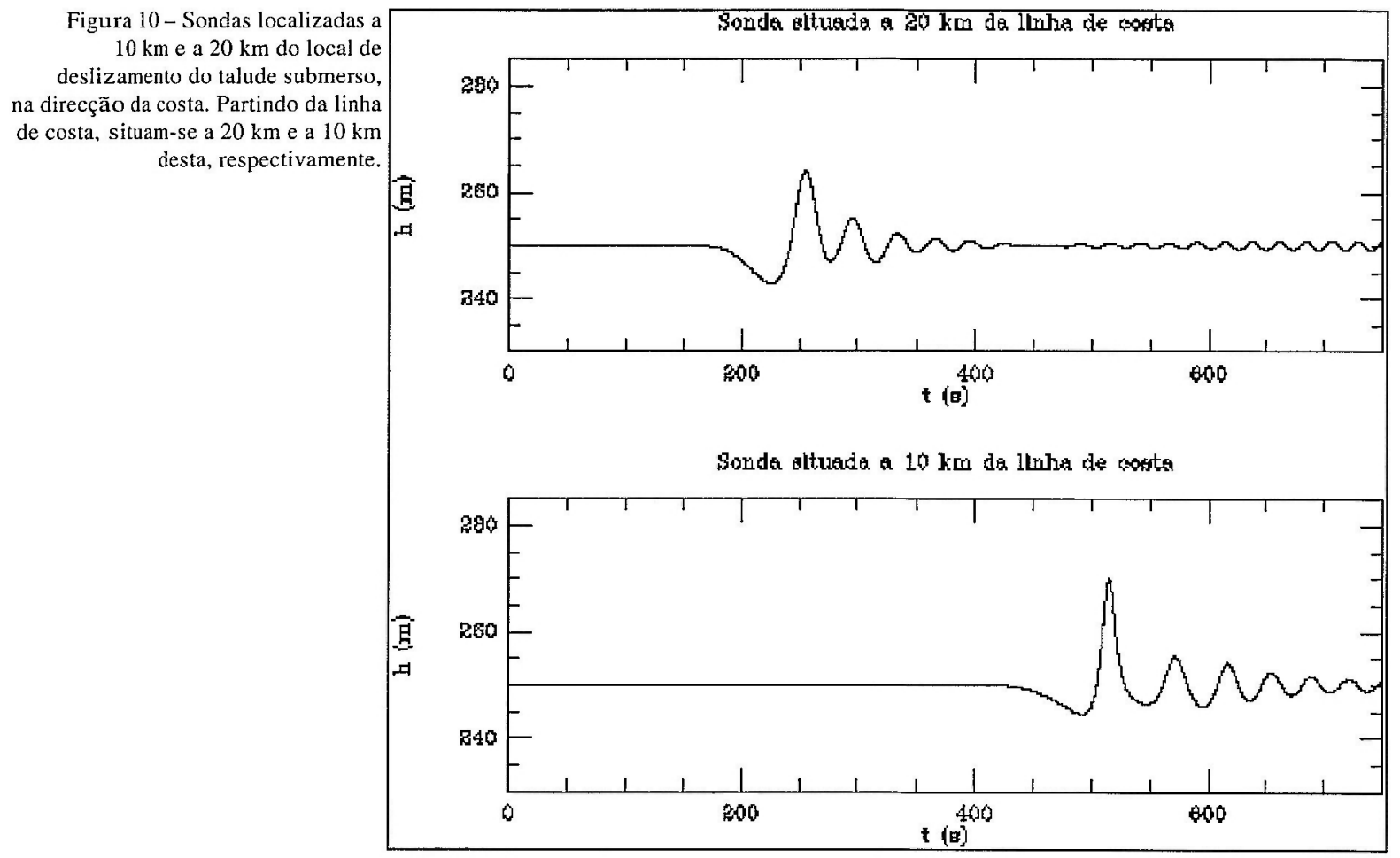

imagem representa a configuração final do fundo, que é atingida vinte segundos após o início do deslizamento do talude submerso, e a configuração da superfície livre três minutos após o início da perturbação.

Importa realçar que o exemplo apresentado pretende simular a geração de um tsunami, e a propagação e aproximação do trem de ondas resultante sobre a plataforma continental; por conseguinte, sobre profundidades decrescentes.

Pretende-se, por outro lado, analisar a velocidade de propagação do trem de ondas geradas e justificar o empolamento da altura, fundamentalmente da onda principal, por efeito de redução da profundidade. A Figura 9 representa configurações da superfície livre aos seis minutos e aos nove minutos após o início do deslizamento do talude submerso. Os resultados apresentados na Figura 10 mostram os instantes de chegada e a passagem do trem de ondas em dois pontos localizados a $20 \mathrm{~km}$ e a $10 \mathrm{~km}$ da linha de costa, respectivamente.

Os resultados apresentados nas Figuras 9 e 10 identificam claramente, no espaço e no tempo, as diferenças de comportamento desta onda ao aproximar-se da linha de costa.

Entre outros aspectos, importa salientar a modificação do trem de ondas, em particular o significativo empolamento da onda principal.

Os instantes de chegada da onda principal a $10 \mathrm{~km}$ e a $20 \mathrm{~km}$ de distância do local de deslizamento do talude submerso são aproximadamente $230 \mathrm{~s} \mathrm{e}$ 500 s, respectivamente (Figura 10). Por conseguinte, realça-se o facto de estarmos já nas proximidades da linha de costa e, em qualquer dos intervalos, a onda ter percorrido $10 \mathrm{~km}$ em menos de 5 minutos.

As diferenças de tempos de propagação da onda nos primeiros $10 \mathrm{~km}$ (distância à primeira sonda) e nos segundos $10 \mathrm{~km}$ (distância entre as duas sondas) demonstra a redução da velocidade de propagação da onda ao aproximar-se da costa (sobre profundidades decrescentes). Com efeito, as correspondentes velocidades de propagação em ambos os intervalos são $C_{1}=43.5 \mathrm{~ms}^{-1} \approx 156.5 \mathrm{kmh}^{-1}$ e $C_{2}=37.0 \mathrm{~ms}^{-1} \approx 133.3 \mathrm{kmh}^{-1}$, respectivamente.

Importa, por outro lado, verificar que a onda se propaga sobre profundidades de $200 \mathrm{~m}$ nos primeiros $10 \mathrm{~km}$, o que corresponde a uma velocidade teórica de propagação $C=\sqrt{g h}=44.3 \mathrm{~ms}^{-1} \approx 159.4 \mathrm{kmh}^{-1}$, bastante próxima da velocidade $C_{1}$ obtida numericamente.

Sublinha-se, por último, que o principal factor que determina as dimensões iniciais de um tsunami é a amplitude de deformação do fundo oceânico. Outros factores igualmente relevantes são: a batimetria, a configuração da linha de costa, a velocidade de deformação do fundo, a profundidade na zona de geração e a eficiência com que a energia libertada é transferida para a coluna de água. Por conseguinte, todos estes factores conjugados darão origem a diferentes configurações do trem de ondas produzido. 


\section{Sistemas de aviso}

Os tsunamis têm amplitudes reduzidas nas proximidades das zonas de geração e, de um modo geral, durante todo o percurso que realizam em grandes profundidades, em geral superiores a cerca de 2000 $\mathrm{m}$ a $3000 \mathrm{~m}$. Por conseguinte, os tsunamis são difíceis de visualizar ao largo (em mar alto), mesmo a partir de observações aéreas.

Para a previsão e alerta de ondas de grandes dimensões, os sistemas de aviso usam ondas sísmicas com velocidades bastante superiores às dos tsunamis, frequentemente na ordem de 10 a 15 vezes mais elevadas.

Se uma perturbação de origem sísmica que atinge a superfície oceânica for suficientemente elevada, de modo a poder ser considerada capaz de produzir um tsunami, é dado um alerta. Nesta conformidade, poderá ou nãoter ocorrido um tsunami; existe, todavia, uma forte probabilidade de este ter acontecido.

De um modo geral, sismos com magnitude inferior a cerca de 6.5 na escala de Richter não são considerados tsunamigénicos (capazes de produzir tsunamis).

$\mathrm{O}$ actual e mais evoluido sistema de aviso de tsunamis montado no Pacífico liga cerca de 50 estações de registo espalhadas ao longo da linha de costa. Uma vez detectada actividade ondulatória não usual e potencialmente reveladora de tsunamis, por uma qualquer estação de registo situada nas proximidades do ponto de geração, é imediatamente transmitida a informação de aproximação de uma onda com efeitos destrutivos potencialmente elevados e os correspondentes tempos de chegada a todas as estações com fortes probabilidades de virem a ser atingidas.

Em geral, este aviso acontece uma a poucas horas antes da chegada do tsunami, nada mais permitindo que a evacuação de pessoas de zonas sensíveis e, eventualmente, de alguns barcos atracados em Portos.

\section{Eefeito meteorológico produzido em Agosto de 1999}

No dia 22 de Agosto de 1999, pelas 14 horas, com as praias do Algarve cheias de veraneantes, foi dado o alarme de que uma onda gigante (tsunami) se aproximava da costa. As praias foram rapidamente evacuadas tendo-se estabelecido o pânico em vários locais. $\mathrm{Na}$ origem deste alarme esteve um efeito meteorológico que parecia ser uma "onda" no horizonte em fase de rebentação e que se aproximava do litoral (Figura 11). O pânico criado manteve-se durante pelo menos uma hora e meia.

Esta "onda", a ser real, situar-se-ía a uma distância da costa não superior a cerca de uma dezena de quilómetros. Por conseguinte, nestas circunstâncias

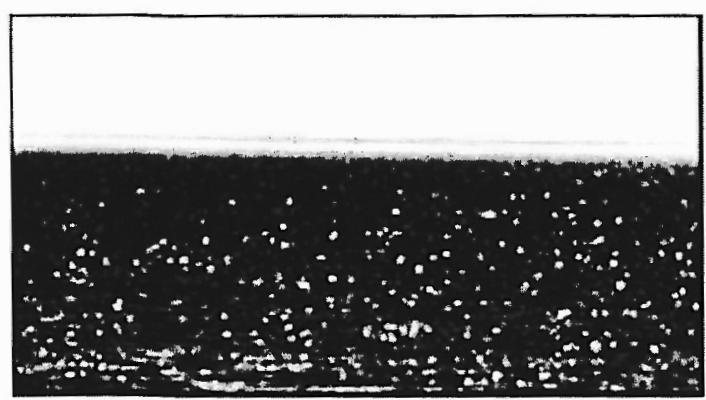

Figura 11 - Fotografia obtida em Agosto de 1999: efeito meteorológico produzido no horizonte (Cortesia de Alveirinho Dias).

seria manifestamente impossível o estabelecimento de qualquer plano de evacuação de uma praia.

Naturalmente, a não existência de qualquer sistema de aviso que permita detectar um potencial tsunami a largas dezenas de quilómetros da costa, deixa-nos completamente desprotegidos em relação a qualquer ocorrência deste tipo. No entanto, face aos dados disponíveise apesar da grande densidade populacional do litoral Português, aceitamos que esta não seja a maior prioridade do nosso País em termos de defesa e protecção da orla costeira.

\section{Conclusões}

São gerados anualmente em todo o Globo muitos tsunamis de pequenas dimensões. Historicamente, um tsunami já com forte poder destrutivo ocorre algures, em parte incerta do Globo, em cada período de dois a três anos. Um tsunami de elevadas proporções, com características devastadoras, ocorre em cada período de quinze a vinte anos.

$\mathrm{Na}$ costa Portuguesa, os períodos de recorrência de tsunamis gerados por sismos com idênticas magnitudes são incomparavelmente superiores. Da ordem de quatrocentos anos para um tsunami com algum poder destrutivo (p.e. quando gerado por um sismo com magnitude da ordem de 8.0 na escala de Richter) e superior a mil anos para um tsunami com características destrutivas e modificadoras da linha de costa, como o ocorrido em 1755. Por conseguinte, Portugal situa-se numa região do Globo com baixa probabilidade de ocorrência de tsunamis com elevado poder destrutivo. Com efeito, embora ocorram sismos com alguma frequência, estes têm em geral magnitudes reduzidas e não geram tsunamis, ou se os produzem não revelam importantes efeitos devastadores. Ainda assim, importa salientar que as zonas de Portugal potencialmente mais vulneráveis, se situam na orla costeira Atlântica situada a sul do Cabo da Roca, na costa Mediterrânica e no Arquipélago dos Açores. 


\section{Agradecimentos}

Ao Professor Pedro Proença Cunha do Departamento de Ciências da Terra da Faculdade de Ciências e Tecnologia da Universidade de Coimbra agradeço a informação bibliográfica que me facultou e o mapa apresentado na Figura 6. Também ao Professor Alveirinho Dias da Unidade de Ciências e Tecnologias dos Recursos Aquáticos da Universidade do Algarve são devidos agradecimentos pela cedência da imagem apresentada na Figura 11.
Bibliografia

ANTUNES DO CARMO, J. S. (1995) - Contribuição para o Estudo dos Processos Morfodinâmicos em Regiōes Costeiras $e$ Estuarinas. Tese de Doutoramentoem Ciências da Engenharia, Universidade de Coimbra.

GOMESPAULINO,J.M.O.(1997)-Sedimentologia, Litoestratigrafia e Geoquímica do Depósito Sedimentar Associado ao Tsunami de $I^{\circ}$ de Novembro de I755 na Boca do Rio, Algarve. Dissertação de Mestrado apresentada à Faculdade de Ciências da Universidade de Lisboa para obtenção do grau de Mestre em Geologia Económicae Aplicada, ramo Geologia do Ambiente.

PEREIRA DE SOUSA (1919) - O Terramoto de I de Novembro de 1755 em Portugal. Vol. 1, Mem. Serv. Geol. Port.

THURMAN, H. V. e TRUJILlO, A. P. (1999) - Essentials of Oceanography. $6^{a}$ edição, Prentice-Hall, Inc., ISBN 0-13$-727348-7$. 